\title{
UNA APROXIMACIÓN AL HOMENAJE DE PAPELES DE SON ARMADANS A LOS 60 AÑOS DE DÁMASO ALONSO: EL CÓMO, EL QUIÉN Y LOS TEXTOS
}

\author{
RODRIGO PARDO FERNÁNDEZ \\ Universidad de Granada
}

\begin{abstract}
Resumen
Este trabajo pretende destacar distintas propuestas para el estudio y la comprensión de la figura de Dámaso Alonso, a partir de una aproximación al proyecto de Camilo José Cela, desde la revista Papeles de Son Armadans, y Emilio Prados de realizar una antología de la Generación del 27, que al cabo se concretó sólo en un homenaje a Vicente Aleixandre, Dámaso Alonso y Federico García Lorca, en conmemoración de sus 60 años (1898-1958).
\end{abstract}

Palabras clave: Dámaso Alonso, antología Generación del 27, Camilo José Cela, Papeles de Son Armadans, Emilio Prados

\begin{abstract}
This work tries to emphasize different offers for the study and the comprehension of Damaso Alonso's figure, from an approximation to Camilo Jose Cela's project, from the magazine Papeles de Son Armadans, and Emilio Prados of realizes an anthology of the Generation of 27, which to the end made concrete only in an honoring to Vicente Aleixandre, Dámaso Alonso y Federico Garcia Lorca, in commemoration of their 60 years (1898-1958).
\end{abstract}

Key words: Damaso Alonso, anthology Generation of 27, Camilo Jose Cela, Papeles de Son Armadans, Emilio Prados

\section{Esbozo del 27}

L

a llamada generación del 27, la nómina a la que suele referirse, está formulada en las antologías que publica Gerardo Diego (1932 y 1934) -a partir de las convenciones de generación propuestas por Ortega en la Revista de Occidente, retomadas por Dámaso Alonso y sus discípulos ${ }^{1-}$, o al menos se establece la relación de sus miembros más destacados.

Se habla también de generación del 25 (por ser la fecha supuesta en la que varios miembros del grupo publicaron sus primeras obras ${ }^{2}$ ) o generación de la

\footnotetext{
${ }^{1}$ Cfr. Alonso, 1965: 166-169.

${ }^{2}$ Lo cual es fácilmente refutable, como evidencia la relación de los autores y de sus primeras obras publicadas: Salinas, Presagios (Madrid, 1923); Guillén, Cántico (Madrid, 1928); Diego, El romancero de la novia (Madrid, 1920); Alonso, Poemas puros. Poemillas de la ciudad (Madrid, 1921); García Lorca, Libro de poemas (Madrid, 1921); Alberti, Marinero en tierra (Madrid, 1924); Aleixandre, Ámbito (Málaga, 1928); Cernuda, Perfil del aire (Málaga, 1927); Prados, Tiempo (Málaga, 1925); Altolaguirre, Las
} 
Dictadura (ya que la formación y primeras publicaciones del grupo coinciden con la dictadura de Primo de Rivera, entre 1923 y 19293).

A partir de este acuerdo tácito (de llamarla generación, de referirla a 1927, fecha en que se celebra el tricentenario de Góngora, y que relaciona a estos escritores a partir de un homenaje al poeta cordobés en Sevilla ${ }^{4}$ ), la crítica literaria, y en muchos sentidos, los propios escritores comprendidos en esta categoría han aceptado la denominación, lo que ha conducido a la publicación de diversas antologías, en las que, nombres más nombres menos, suele considerarse a los siguientes poetas, catalogados y estudiados por parejas: Pedro Salinas/Jorge Guillén, Gerardo Diego/Dámaso Alonso, Federico García Lorca/Rafael Alberti, Vicente Aleixandre/Luis Cernuda y Manuel Altolaguirre/Emilio Prados ${ }^{5}$.

\section{La correspondencia entre Cela y Prados}

Entre Camilo José Cela y Emilio Prados se establece una nutrida relación epistolar de 1957 a 1962, surgida a partir de una iniciativa de Cela: la elaboración del volumen La generación poética del 27. Nueva antología a distancia, suerte de homenaje y pretensión de antología definitiva (más adelante diré por qué) de la generación que se concretó parcialmente.

La antología se redujo considerablemente: de los diez indispensables, por decirlo de algún modo (si bien Cela amplió sus parámetros a varios poetas más), sólo se editó un homenaje a Dámaso Alonso, Vicente Aleixandre y Federico García Lorca, por sus 60 años (1898-1958). Un comentario al margen, sobre la edición: en la portada de la revista sólo aparecen las firmas autógrafas de Aleixandre y Alonso quienes, hay que decirlo, habían permanecido en España al finalizar la guerra sin mayores problemas, en términos políticos. Lorca, a pesar de las contadas pero constantes ediciones de algunas de sus obras en la península entre 1939 y 1958, arrastraba consigo diversos estigmas, relacionados con su postura política (no radical, pero sí incómoda) y su temprano asesinato. Lorca sufre cierta discriminación que capea la censura franquista; la transcripción del texto que reproduz-

islas invitadas y otros poemas (Málaga, 1926). Por tanto, la convención de generación del 27 quizá sea más comprensiva.

${ }^{3}$ El poeta Emilio Prados formula su particular propuesta a partir de la labor que desempeñó la editorial Sur, a su cargo, en Málaga en torno a la revista Litoral; habla entonces del grupo de Litoral.

${ }^{4}$ Ignacio Sánchez Mejía fue el mecenas del homenaje y Gerardo Diego uno de sus principales promotores; el homenaje trascendió a publicaciones como Litoral, que dedica un número a Góngora en octubre de 1927, y a estudiosos como el mexicano Alfonso Reyes, quien envía su colaboración como parte de su esfuerzo de rescatar la figura gongorina (1927); desde 1910 y antes de viajar a España (como puede verse en su conferencia juvenil "Sobre la estética de Góngora") había comenzado esta campaña por la reivindicación del poeta.

${ }^{5}$ En varios momentos y espacios uno $\mathrm{u}$ otro de los poetas considerados pretendieron distanciarse, diferenciarse, eludir este membrete, por razones poéticas o personales; p.e. Cernuda (1981: 37): “Si yo pertenezco o no pertenezco a la susodicha generación [la del 25], es una cuestión, y otra el que no tenga ganas de aparecer junto a un grupo de gentes que nunca me entendieron"; o bien el propio Dámaso Alonso, cuando señala: “... las doctrinas estéticas de hacia 1927, que para otros fueron tan estimables, a mí me resultaron heladoras de todo impulso creativo. Para expresarme en libertad necesité la terrible sacudida de la guerra española" (Alonso, 1965: 169, nota). 
co (y la foto que le sigue), que se sitúa en la revista tras la editorial de Cela (1958), no aparece mencionada en el índice:

\author{
10 abril 1931 \\ Dentro de la verja canta la fuente \\ que oyen Dámaso y Vicente. \\ Con el libro y el sombrero \\ Dámaso ríe el primero \\ y Vicente con su pañuelo \\ sueña un paisaje de hielo. \\ Pero yo que soy Federico \\ muevo en su honor alas y pico. (García Lorca, 1958: 119)
}

Partiendo de la lectura crítica de la correspondencia ${ }^{6}$ entre México (en la distancia del exilio) y Palma de Mallorca (bajo la sombra de la dictadura) puede seguirse (desde una perspectiva quizá limitada, pero al mismo tiempo esclarecedora), en orden cronológico y observando la adecuación paulatina de los criterios para elaborar la antología, lo que fue un proyecto fallido (en parte, dado que rescató al menos a tres poetas) de realizar un compendio personal y crítico del 27 y otros poetas que se considera participan de su órbita.

Vale acotar, a modo de introducción, el marco esencial en el cual Cela, desde su revista PSA (en la tradición que había iniciado Ínsula ${ }^{7}$, pero aproximadamente una década más tarde), realiza un rescate, una aproximación a los escritores españoles en el exilio; en este contexto se ubica la intención de Cela, quien escribe en Palma de Mallorca, con fecha 26 de marzo de 1958:

... Con motivo de los sesenta años de la generación del 27 (en este 1958 llegan a esa edad Dámaso y Vicente, y hubiera llegado Federico...) preparo un homenaje al que pienso titular La generación poética del 27. Nueva antología a distancia. Sé bien que usted prefirió no figurar en la Antología de Gerardo y respeto, claro es, sus puntos de vista de entonces. La Antología que ahora preparo llevará los mismos nombres que la $1^{\mathrm{a}} \mathrm{de} \mathrm{Ge}-$ rardo y a usted quiero decirle, muy en privado, una cosa: si usted no quiere figurar, no hay Antología. (Cela, 1996: 50)

La intención de Cela se precisa en los requerimientos que hace a Prados para su inclusión en la antología, en primer lugar:

... Si me dice que sí, cosa que tanto deseo, me permito rogarle que me envíe:

Ficha biográfica detallada.

Ficha bibliográfica detallada.

Declaración estética.

\footnotetext{
6 "Los epistolarios de poetas contemporáneos españoles no han revelado hasta la fecha grandes cosas: en ellos predomina la chismografía más o menos elegante y casi siempre intrascendente, que, en el mejor de los casos, sólo sirve a los eruditos." (Carreira, 1996: 36); esta afirmación sólo es parcialmente cierta, teniendo en cuenta la importancia de las anécdotas y las circunstancias de los escritores (hombres comunes y silvestres) como sujetos históricos en el devenir de la práctica sociocultural que llamamos literatura.

${ }^{7}$ Revista de gran importancia en la España de la posguerra, por su difusión y por su suerte de apertura a los escritores exiliados; fue fundada en 1946 por Enrique Canito y José Luis Cano, y se sigue editando hasta la fecha.
} 
Selección de poemas (para unas 15/20 páginas de texto), ya que aspiro a que los poetas vengan representados según su voluntad.

Foto inédita. (Cela, 1996: 50)

Cuando Cela (1996: 55) añade a su solicitud, el 27 de abril de 1958, un “Juicio crítico a distancia de la generación del 27.", Prados “... se zafa de un encargo que sin duda le resultaba molesto y doloroso, alegando que su pertenencia al grupo le impide tener la suficiente perspectiva como para juzgarlo de forma objetiva." (Chica, 2002: 15). Los términos en que se niega (y al tiempo, mediante los cuales sustenta el por qué se les puede considerar una generación, formulándose aquello que los une y los diferencia) son los siguientes:

[México 6 de mayo 1958] Hoy hay que ponerse formalito para la Antología. A eso voy. Vd. me decía que hiciera una "crítica a distancia" de mi generación. Y yo le voy a decir que "por los clavos de Cristo" no me meta, ni nos meta en ello. Hay varias causas: la primera para mí es que yo estoy dentro de esa generación y no tengo (y no creo que pueda tener) una perspectiva clara de ella. La segunda (o tal vez más exactamente, esta es la primera de las causas) es que fuimos y seguimos siendo un grupo de amigos, "itan amigos!" que, aunque hoy estemos alejados aparentemente por la vida, cada cual lleva en su alma ese pedacito que se rompió -para unirnos más- de la piedra unidad que somos y seremos por encima del olvido mismo. (Prados, 1996: 58)

Esta idea de "generación de la amistad" es también utilizada, en términos favorables, por Claudio Guillén, a partir de la correspondencia y los artículos de su padre, Jorge Guillén, y el estudio del grupo en su contexto vital, antes y después del homenaje a Góngora, en primer término, y durante la guerra civil y con posterioridad a ella. Para complementar su visión de la generación, de la que se siente parte indisoluble, Prados continúa:

\footnotetext{
El "Símbolo" esta vivo y aquí, o en la memoria de Dios o de algún hombre, cada uno de nosotros llevará el trozo de piedra que le tocó en suerte, al ser partida ella. Y al encajar cada trozo en su sitio, misteriosamente, se sentirá como renacer en la unidad o generación o grupo, de la amistad, constante. Ya se lo digo: hoy el símbolo está herido solamente: Y yo no quiero tocar esa herida. Quiero, sí, pensar siempre en que sigue viviendo. ... Otro motivo -aunque parezca contradictorio con lo que acabo de decir- es que mi generación se formó, no por acuerdo, sino por encuentro. (Prados, 1996: 58-59)
}

En palabras de Miguel Ángel García, hay que historizar los textos, los poemas y las posturas críticas. Así como el contexto no determina en relación de causa y efecto al autor, es necesario tener en cuenta los procesos históricos que rodean y de los que participa el escritor, que lo transforman y en los cuales, en menor o mayor medida, incide. En su momento, varios de los poetas del 27 quedaron relegados en España como figuras aisladas y en cierta medida incomprendidas, a causa de la censura que se evidenciaba en el silencio editorial, en la poca difusión. Además, el distanciamiento pudo deberse, hasta cierto punto, a la línea 
más conservadora de la lírica en ese periodo, así como a las propuestas de la llamada poesía del compromiso, tan distintas incluso de la poesía rehumanizada ${ }^{8}$.

La perspectiva que construye y defiende Prados en su correspondencia con Cela, partiendo del pretexto de la antología propuesta en PSA y de los requerimientos del proyecto, queda perfectamente delineada en este sentido, es decir, en tanto define su propio quehacer poético, en términos de su coincidencia con la generación del 27, en un primer momento, y más tarde de su reflexión, basada en la experiencia, sobre lo que es su poesía 20 años después:

[México 12 de junio 1958] Tus deseos de unirnos de nuevo en una Antología ¡homenaje!- me ha hecho pensar en mí, en mi poesía. Y tus terribles palabras de "los que cumplen, cumplirán o van a cumplir 60 años ahora", más todavía. A esto se ha unido, misteriosamente, la "separación" de Juan Ramón Jiménez, último hilo que nos unía -de cierta forma cautivos- a un tiempo. (Prados, 1996: 70-71)

Su entusiasmo por la antología que nunca fue se debe, en el fondo, a su interés en que se reconozca la dimensión, los aportes de una generación que, en los años 50, sufría de la distancia, geográfica y poética, tras la diáspora en 1939, por una parte, de los disidentes políticos del bando vencedor de la guerra civil española; por otra, la permanencia en España de quienes, de una u otra manera, estuvieron de acuerdo con el régimen franquista.

Quizá lleno de pavor por aquellos "terrores nocturnos" de la infancia, que forman su carácter voluble (ahora entusiasta, ahora tendente a la depresión), o bien humilde frente a su trabajo y frente a la destacada obra de otros miembros de la generación del 27, Prados, ante la invitación expresa de Cela para que formule su "declaración estética", arguye:

[México, 7 de abril 1958] La "declaración estética" me aterra, porque yo ¿cómo voy a declarar un misterio del que me siento entraña? Pero cuando le escriba de ello trataré de expresar lo que siento con, de, en, por, sin, sobre, tras la poesía. (Prados, 1996: 53)

Para cerrar este breve apartado vale la pena mencionar una aseveración de Juan Carlos Rodríguez, referida al conjunto de los poetas del 27, representados por Alberti, Guillén, Lorca, Cernuda:

... no son otra cosa que única y exclusivamente poetas: en todos ellos alienta clarísimamente la determinación básica de que su vida consiste en el hecho de escribir poesía ... escribir como una manera cotidiana de vivir: la poesía convertida en Diario, el Diario convertido en poesía. (Rodríguez, 1994: 286)

La poesía preside la vida y la práctica de quienes conforman la generación de 27. Se debe destacar la influencia de la poesía pura juanramoniana, reconoci-

\footnotetext{
${ }^{8}$ La denominada poesía del compromiso o poesía social (Gabriel Celaya, Blas de Otero, Victoriano Crémer, José Hierro), en términos de Antonio Chicharro (2002: 76), “... trata de llevar hasta sus últimas consecuencias ... los presupuestos poéticos de la temporalidad machadiana y de la ideología de la rehumanización"; varios de sus representantes, vale anotarlo, colaboran en el homenaje a Aleixandre, Alonso y García Lorca que nos atañe: Celaya, Hierro, etc.
} 
da o denostada. Subyace, siempre, la idea del vitalismo poético, esbozado en los versos de Juan Ramón: "oh poesía / pasión de mi vida".

En términos de una dicotomía, que si bien corre el riesgo de simplificar un fenómeno complejo permite esclarecer el pensamiento y la práctica de la poesía española de vanguardia, se establecen posturas "opuestas" debidas a una escisión: por un lado, la literatura (anecdótica, literaria, ideológica, moral, narrativa), y por otro, la poesía pura, esencialista. Se trata, a fin de cuentas, de la oposición entre la sustancia (la esencia) frente a la forma. Se debe indicar, por otra parte, la estrecha relación, frente al romanticismo, entre la deshumanización del arte (propuesta por Ortega en la Revista de Occidente, 1925) y la poesía pura.

Prados se posiciona en el 27, defendiendo una clara postura generacional desde su punto de vista, que se acerca a la de los otros poetas:

[México 6 de mayo 1958] Y no piense Vd. como otros lo hacen que nos pensábamos -en nuestro "símbolo" - como elegidos y que la vida en cualquier forma no nos hacía vibrar. Al contrario, nos hacía vibrar en todas sus formas, y principalmente en la humana, pero sin saberlo, no supeditábamos la poesía a una servidumbre parcial de esta vida. Y cuando alguna vez "los versos" nuestros, no "la poesía", lo hizo, nos faló nuestro mundo interior -a mí a lo menos- $\mathrm{y}$, aunque la vibración fue dada sinceramente, tuvo el que lo hizo que cambiar su rumbo... (Prados, 1996: 61)

De este modo Prados remite, de nuevo, al arte por el arte, a la pretendida poesía pura, quizá, que propuso y defendió en su momento Juan Ramón Jiménez; y además puntualiza lo que Cela está proponiendo, lo sitúa en su ubicación con respecto a otros intentos de revistas y editoriales de la época. Por otra parte, le hace una serie de sugerencias, la más importante de ella la posibilidad de que el propio Cela realice un estudio crítico, el cual, a juicio de Prados, será de mayor validez que la opinión de quienes participan del 27, dado que Cela los analiza, critica, a distancia:

Pero todo esto lo sabe Vd. mejor que yo. La prueba de ello es que Vd. es el que trata de reunirnos. Ya sé que otros han escrito sobre esto pero el reunirnos en la poesía, lo simbólico que yo deseaba, lo va o quiere hacer Vd. Por eso creo que es Vd. el que debía encabezar la Antología con un estudio crítico a distancia. Porque es Vd. el que tiene esa distancia. He leído su magnífico estudio sobre Solana y creo que podía hacer una cosa parecida. No espere a que estemos todos bajo tierra. Si quiere yo le ayudo, dándole los datos que pueda. La Antología me parecería mejor con las noticias sobre vida y libros de cada uno. Lo demás temo que sea difícil, pues en nosotros los tránsitos fueron explosiones internas y $\mathrm{Vd}$. conoce las manifestaciones de ellas. (Prados, 1996: 61)

Al estudio que refiere Prados es a "La obra literaria del pintor Solana", discurso de Cela en su ingreso a la Real Academia Española en 1949, que se constituye como uno de los más claros ejemplos (por su profundidad, su extensión, sus alcances) de la obra crítica de Cela. 


\section{El proyecto de Cela}

Como se evidencia en el conjunto de la correspondencia, Prados siempre tuvo la mejor disposición para participar en la antología; no fue el caso, como ya se sabe, de las primeras antologías elaboradas por Gerardo Diego, en la primera de las cuales aparece a regañadientes, y en la segunda se "niega" a participar. En sus palabras:

[México 7 de abril 1958] ... al hablarme [de la Antología de Diego] me hace ver lo irresponsable que soy con la "palabra" (prefiero llamar de esta manera a mi poesía). Lo digo porque la verdadera negación mía, para figurar en la Antología, fue refiriéndose a la $1^{\mathrm{a}} \mathrm{A}$. Mi actitud entonces era "feroz", y recuerdo que le dije a Gerardo "yo no conozco a Emilio Prados"... y otras variantes del mismo tono. Cuando se iba a editar la $2^{\text {a }}$ A., me dijo Gerardo: "si no recibo carta tuya, para esta fecha, es que no deseas tomar parte en el libro". Y yo, por flojera, lo fui dejando... (Prados, 1996: 51)

El siguiente fragmento plantea los requerimientos de Cela, es decir, los criterios (los autores, los textos, la información, los documentos) que pensaba tomar en cuenta para incluirlos en su antología. Además precisa, como límite o referente a Jorge Guillén (1893-1984), y deja a un lado a Moreno Villa (18871955). Más adelante cambiaría de opinión, en una suerte de ajuste a la idea original, pero lo que importa en este caso es el proceso, el toma y daca de un proyecto que, si bien no llegó a concretarse, significó un intento claro de repensar el 27, sin cuestionar el membrete de generación, cuando la mayor parte de quienes lo conformaron estaban vivos, en España o en el exilio (mayormente americano).

[Palma de Mallorca, 27 de abril de 1958] Gracias por sus líneas y por su ofrecida colaboración. Yo creo que la Antología -no le llamemos Homenaje, puesto que usted lo pide- puede quedar muy bella y, como documento, muy interesante. ... Lo que yo quiero que me mande es lo siguiente:

Nota biográfica detallada.

Nota bibliográfica detallada.

Foto actual e inédita, no pequeña y en negro esmaltado, que reproduce mejor.

Poemas para 20 o 25 páginas.

Juicio crítico a distancia de la generación del 27.

Sé que es mucho, pero también sé que es necesario. A mi admirado Moreno Villa no lo voy a incluir, por viejo. La Antología se limita, precisamente, a lo que, con mayor o menor exactitud, venimos llamando la generación del 27, con Jorge Guillén como límite de edad. (Cela, 1996: 55)

En su correspondencia con Prados, en muchos sentidos, se va esbozando el modo en que la antología será conformada, lo que permite establecer algunos parámetros: el orden de lo poetas, siguiendo la propuesta de Gerardo Diego (1932 y $1934^{9}$ ), dado su carácter fundador de la generación, no de los poetas comprendidos

\footnotetext{
9 Sobre Diego y el volumen que se propone realizar, Cela comenta: “[Palma de Mallorca, 3 de noviembre de 1958] ... Gerardo ... Conoce, naturalmente, mi proyecto de Antología, en la que él es uno de los poetas que figuran. Los temores que albergaba (Gerardo es hombre que alberga los temores) procuré deshacérselos y me figuro que ahora está contento con mi proyecto en cuya Introducción,
} 
bajo un concepto particular de hacer poesía sino de quienes compartieron una intención poética, y sobre todo, un tiempo determinado.

[Palma de Mallorca 22 de junio 1958] Los poetas irían, en el futuro libro, colocados siguiendo -o casi siguiendo, ya veremos- el "orden lógico" que empleó Gerardo y que, no siendo óptimo, es, al menos, el más aceptable, y el orden de publicación en la revista, claro es, nada tendría que ver con este orden definitivo, que se aclarará en una breve nota previa y que se indicará en cada caso. (Cela, 1996: 73)

En esta carta Cela señala también que, antes de conformar un libro unitario, una antología acabada (en un solo volumen) que dé fe de quienes participan de la generación del 27, piensa publicar a los poetas en PSA de manera independiente, de acuerdo con el acopio de información sobre cada uno de ellos, desde sus poemas hasta su retrato fotográfico. Considerando que Cela se erige como antologador y compilador, afirma que esta publicación progresiva de los poetas:

... me permitiría una perspectiva y un detenimiento que redundaría en beneficio de la obra, que aspiro a que sea una aportación llena de seriedad y de solvencia. ... Mi ensayo de interpretación, entonces, no iría como prólogo sino como epílogo, lo que quizás fuere más conveniente, ya que no se trata de descubrir sino de comentar. (Cela, 1996: 74)

Por otra parte, Cela ha modificado su criterio "de edad", esto es, la inclusión de unos u otros poetas por su fecha de nacimiento, ampliando así la antología y comprendiendo de ese modo no sólo a la nómina básica del 27, sino a todos aquellos poetas que, de un modo u otro, participaron de la intención de renovar (modernizar, quizá, sería la palabra, en su sentido lato) la poesía española y compartieron, desde perspectivas distintas pero de muchos modos complementarias, procesos históricos tan diversos como las vanguardias artísticas; los adelantos tecnológicos de las primeras décadas del siglo XX; la herencia del 98 y el modernismo de Rubén Darío; la dictadura de Primo de Rivera, la segunda república y la guerra civil; y muchos de ellos, al fin, el exilio. Cela reconoce:

He revisado mis anteriores puntos de vista y he decidido incluir también a nuestro llorado José Moreno Villa10; es cierto que es mucho más viejo que vosotros, pero cierto es que más viejo aún es Villalón [1881-1930], y va. (Cela, 1996: 75)

En otro momento continúa la ampliación de su perspectiva: "[Palma de Mallorca, 6 de julio de 1958] Juan Larrea sí va (Domenchina, no)." (Cela, 1996: 78), y más allá, establece de modo más o menos definitivo los criterios que, sin embargo, no llega al fin a poner en práctica:

[Palma de Mallorca, 3 de noviembre de 1958] No voy a cambiar el plan de mi Antología. Voy a ocuparme de "vosotros", [del 27] los que vais desde Salinas [1892-1951] hasta Manolo Altolaguirre [1905-1959], incluido, claro es, el desplazado Fernando Vi-

como es lógico, se le alude constante y cariñosamente." (Cela, 1996: 103). La nueva antología de Diego sobre el 27 se editó en 1959, al contrario de la de Cela.

${ }^{10}$ Ver carta de Cela fechada 27 de abril, 1958: “A mi admirado Moreno Villa no lo voy a incluir, por viejo." 
llalón [1881-1930], aunque es posible que dé dos más viejos (León Felipe [1884-1968] y José Moreno Villa [1887-1955], ¿qué te parece?) que se anticiparon, en cierto modo, a su tiempo. (Cela, 1996: 103)

Para entender en toda su dimensión la importancia de una antología del 27 a fines de la década de los 50, en la España franquista, con la mayor parte de los poetas en el exilio por su postura política, cuando en la península se guarda un silencio obligado con respecto a ellos (roto, en momentos, por breves y aisladas ediciones, algún homenaje en revistas que no tenían grandes tiradas, artículos diversos y por lo general, debido a la censura, inocuos sobre los protagonistas del 27), vale analizar el (breve) colofón de Cela a esta carta: “Creo que quedará interesante la Antología y que servirá para descorrer muchos estúpidos telones y ahuyentar multitud de negras y pegajosas nubes. Confiemos en ello." (Cela, 1996: 75).

Los "estúpidos telones" y las "negras y pegajosas nubes" pueden ser interpretados de distintos modos. Los telones remiten a algo que se cierra, esto es, una concepción hermética: parece que no hay más que decir (hablamos de 1958) sobre el 27, que todo está escrito teniendo como referente a la aparentemente antología total, absoluta, de Gerardo Diego: están dados los nombres y las fechas, definidas las posturas y las propuestas, pareciera agotado el filón y perfectamente delimitada la generación.

Por otra parte, y esto es lo fundamental, se ha dado vuelta a la página, teniendo en cuenta la censura franquista, el mutis impuesto sobre quienes se opusieran al régimen, desde el arte, la filosofía, la praxis, la postura ideológica de cualquier signo. Cuando se habla de telones bien podría decirse membretes, cajones cerrados.

En otro sentido (e insisto en que se trata de una mera elucubración) las "negras y pegajosas nubes" bien pueden remitir a las nuevas tendencias (a "la sombra del caudillo") de la poesía y del arte que, apropiándose o rescatando técnicas y temáticas del 27, reniegan de su influencia y hacen lo posible por desdibujar su importancia.

Leyendo la correspondencia que mantiene Cela con Prados, a fines de 1958 le comenta lo siguiente: "[Palma de Mallorca, 3 de noviembre de 1958] ... mi antología marcha. Como sabes, la voy a dar antes, poeta a poeta, en Papeles. El orden lo marcaré en la Introducción y el de la publicación vendrá siempre referido a aquél. Quisiera, por misteriosas razones afines, empezar contigo." (Cela, 1996: 102). Los 20 poemas enviados por Prados para la antología, en el orden propuesto por Cela, fueron publicados hasta 1996, como apéndice a la correspondencia entre ellos (Prados, 1996b: 168 y ss.) ¿En qué quedó esa antología cuando finalizaba 1958?

\section{La antología inconclusa}

La proyectada antología a la generación del 27, como ya mencioné al principio, se concretó (se redujo) a un homenaje a Vicente Aleixandre, Dámaso Alonso y Federico García Lorca, en conmemoración de sus 60 años (1898-1958). Lorca es el único de los tres que había muerto, pero al mismo tiempo era el es- 
critor más arriesgado para editar, dadas las circunstancias de su muerte y la perspectiva de la censura.

Con fecha 31 de diciembre de 1958 impresa en el colofón, aparece el volumen doble, XXXII-XXXIII, de PSA. De acuerdo con la idea original de Cela, "Con motivo de los sesenta años de la generación del 27 (en este 1958 llegan a esa edad Dámaso y Vicente, y hubiera llegado Federico...) preparo un homenaje al que pienso titular La generación poética del 27. Nueva antología a distancia." (Cela, 1996: 50), este número de la revista se conforma como un homenaje y no como una antología, y se limita sólo a las tres figuras citadas.

Hay dos matices que indicar: en primer lugar, la mayor parte de los poetas que hubieran figurado (de acuerdo con los criterios de Cela) colaboran en esta PSA, si bien en relación con la generación o con alguno de los poetas que cumplen 60 años: es el caso de Alberti, Aleixandre, Guillén, García Lorca y León Felipe, pero la publicación de sus respectivos dossier, incluyendo la amplia información requerida por Cela, nunca vio la luz.

En segundo término, y no por ello menos importante, es la exclusión de Emilio Prados, a pesar de la correspondencia y afirmaciones de Cela en este sentido. Escribe Prados a Cela, desde México, en febrero de 1959:

... En casa de tu paisano [Jesús Bal y Gay, musicólogo gallego] vi de pasada el número dedicado a V., F. y D. del cual ni me hablaste, ni tenía noticias hasta que supe que estaba impreso. Y al leer el índice de colaboración me ha dado pena. Sí; sí, porque esos tres nombres son de tres amigos míos muy grandes. Y yo soy selvático pero no tanto. (Prados, 1996: 108)

La queja de Prados tiene mucho de razón11; la pronta respuesta de Cela, fechada el 7 de marzo, deja en vilo el desaire, pero lo más destacado es que no explica la razón de este homenaje, ni tampoco el hecho (como se vería más adelante) de que se tratara de la antología (parcial, inconclusa) de la que se había hablado tanto y durante tanto tiempo: “... En el no de los sesentones no colaboras tú. Es cierto. Ignoro por qué y tampoco voy a ensayar una disculpa. Yo me lo he perdido." (Cela, 1996: 110).

\section{Lecturas sobre Dámaso Alonso}

Más allá de anécdotas, esclarecedoras pero no suficientes, es necesario abordar el homenaje que se editó. En este breve estudio no es posible analizar en detalle las más de 400 páginas de que consta este volumen, dedicado a los tres poetas. Sin embargo, sí es factible realizar un primer acercamiento a los textos relacionados específicamente con Dámaso Alonso, considerando que es el autor menos estudiado de los tres, y que dicha aproximación (a partir de

\footnotetext{
11 Aún Prados insiste con este tema más adelante: "[México, 5 de agosto de 1959] ... ¿Y la Antología? ¿Qué le pasa? Ya ves que hasta los jóvenes... Creo que la debieras hacer." (Prados, 1996: 116). Y más tarde, reflexivamente, propone: "[México, 29 de marzo 1960] ... Te quería hablar de muchas cosas. De tus Papeles... ¿Y la Antología? Salió la de Gerardo, la vi anunciada [Diego, 1959]. Yo creo que ahora tendrías que rehacer mucho si la piensas dar. Pero ya, creo que es mejor esperar unos añillos, o un añillo. Hay escrito bastante nuevo desde entonces, crítica y poéticamente. Nunca me volviste a decir nada." (Prados, 1996: 128-129).
} 
distintas perspectivas, que van desde una muestra de las poesías del propio Alonso hasta poemas dedicados en su honor) ayudará a comprender mejor no sólo la figura y la obra del autor, sino cómo era contemplado, cómo se leían sus textos y se establecían diálogos con él en vida. Por tanto, se trata de una referencia de gran importancia para su estudio.

Para facilitar la aproximación y la consulta de la fuente original he optado por conservar el orden de las colaboraciones, tal y como aparecen en la revista (al final se incluye un listado por autor, en orden alfabético); en cada una de ellas he señalado las características formales (tipo de texto, características generales, páginas) y he elaborado un resumen. No pretendo realizar un análisis en profundidad, sino plantear un estado de las cosas que sirva de punto de referencia para una mayor y próxima profundización sobre Dámaso Alonso.

5.1 Camilo José Cela, "Loa de los jóvenes sesentones y llanto por el poeta muerto en flor" $(1958 b)$

Prólogo. Presentación y loa en prosa, 115-118 pp.

A modo de introducción del número, esta loa se refiere a Aleixandre, Alonso y Lorca. Escribe Cela: “... en el hondo y claro pozo en el que habita (gracias, Dámaso), igual que el agua, la poesía”, reconociendo de alguna manera en Alonso su ser poeta antes que crítico ${ }^{12}$, y sobre todo, su papel como profesor, como maestro de otras generaciones. Los tres poetas confluyen en 1898, año de su nacimiento; cuando "España se daba -la silenciosa Españaal noble menester de parir poetas ...".

Precisa Cela: "Dámaso, el 22 de octubre: un 22 de octubre, dando las boqueadas el siglo XVIII, el volador Samerin inventó el paracaídas; otro 22 de octubre, mientras Dámaso soplaba las ocho velitas de su tarta de cumpleaños, se iba para el otro mundo el pintor Cézanne".

En un sentido unificador, afirma: "Este número de los Papeles de Son Armadans ... está dedicado, íntegramente, a la glosa del uno y trino ejemplario de Vicente, Federico y Dámaso, tres personas y una sola poesía verdadera. ... estas páginas ... enarbolan la también blanca bandera de la amistad." Dámaso queda así amparado, en relación estrecha con los otros dos poetas andaluces contemporáneos suyos, en un homenaje que refrenda su figura.

\subsection{Dámaso Alonso, "Poesías ocasionales"(1958)}

Poemas, antecedidos por una nota aclaratoria. Diversos metros y rimas, 125-148 pp.

Se presenta aquí un conjunto heterogéneo de 11 poemas que dan una idea bastante fidedigna de lo que fue el quehacer poético de Dámaso Alonso, dado

\footnotetext{
12 Refiriéndose a su Vida y obra, el mismo Dámaso señala: “... he hablado de mi poesía y de los sitios donde di lecciones, pero no de los trabajos que, llevándome por muchas sendas espirituales, me servían para encubrirme mi vital aflicción [la escritura poética]" (citado por Chicharro, 1991: 16).
} 
que comprenden de 1919 a 1955. Se trata, eso sí, de "poesías escritas para ajustarse a una ocasión", que "ha de entenderse como un asidero a algo muy concreto, entre el vivir diario", en palabras del autor.

Escritas, la mayor parte de las veces, a "vuelapluma", aparecen reunidas en esta ocasión justamente porque "su autor cumple una edad en la que parece que conviene ... ir dejando ya limpio y ordenado el cuarto en que se ha vivido ... nuestro ámbito vital".

Como la selección abarca desde la juventud de Alonso hasta su madurez poética (la que había logrado rondando los 60 años), y estando vinculados los poemas con hechos específicos, tienen un sentido muy personal ("Sé Leticia, como tú eres"; “¡Ah, pobre José Antonio!”) y coloquial (“¡Macho, cuántos papeles!"'). Su mayor valor, quizá, sea anecdótico, en relación a la vida de Dámaso Alonso en distintos lugares, y sobre todo, en cuanto profesor irremediable en su praxis toda.

\subsection{Jorge Guillén, "Algunos poetas amigos" (1958)}

Ensayo. Dividido en cuatro apartados, con numeración romana, 149-165 pp.

En este artículo, de gran importancia metodológica, anecdótica y reflexiva, en lo que se refiere a los diversos intentos por definir la generación del 27, en este caso defendida como la "generación de la amistad", apenas se menciona la figura de Dámaso Alonso, excepto en los fragmentos que refiero a continuación, y que de muchos modos refrendan el volumen de homenaje que editó Cela, y que ahora nos ocupa: "Hacia 1925 se hallaban más o menos relacionados ciertos poetas españoles. Si, según Ortega ... una generación agrupa a hombres nacidos durante un período de quince años, esta generación tendría su fecha capital en 1898: entonces nacen Federico García Lorca, Dámaso Alonso, Vicente Aleixandre".

Quizá la visita a Cela en Palma de Mallorca que llevó a cabo Guillén, con Américo Castro, en el verano de 1958, influyó de alguna manera en que la antología proyectada se redujera a estos poetas únicamente.

\subsection{León Felipe, “Cuatro poemas, con epígrafe y colofón” (1958)}

Poemas. “La cruz", “Credo”, “Balbuceos” y “El infierno”, verso libre, 189-194 pp.

El poeta de Tábara dedica con las siguientes palabras sus poemas: "A mi viejo y docto amigo, el poeta Dámaso Alonso, al cumplir sus sesenta años de edad".

Por la revisión de los índices de PSA es posible concluir que en la revista tampoco León Felipe (como ninguno de los contemplados habitualmente en la nómina de la generación del 27) publicó un conjunto de poemas, su declaración estética, etcétera, es decir, los requisitos que Cela planeó (como escribió a Prados en su momento) incluir en su antología.

Los poemas dedicados a Alonso se acercan a su sentido de lo trascendente, o mejor, a su suerte de diálogo con la divinidad, ese "largo camino de meditación y de interrogación al Dios personal" de Dámaso Alonso (García de la Concha, 2002: 236). Destaca el colofón, poemilla que cierra la reflexión del epí- 
grafe sobre la mirada y el llanto: "Luz... / Cuando mis lágrimas te alcancen / la función de mis ojos / ya no será llorar, / sino ver."

\subsection{Rafael Ferreres, "Sobre la generación poética de 1927" (1958)}

Ensayo. Apartados: “La generación de 1898 y la de 1927” y “Libros iniciales”, 301-314 pp.

Desde Valencia, esta reflexión resulta interesante no tanto por lo que dice acerca de Dámaso Alonso sino por el hecho de que, para reflexionar sobre la generación del 27 se recurre, como autoridad, a su opinión como crítico.

Sobresale en este texto el intento de vincular (y diferenciar) el 98 y la generación del 27, hablando de las influencias y el contacto que pudieron tener. Se ahonda además en las características del 27, si bien se establece claramente que dicha denominación sirve para nombrar un grupo poético, pero "si se quiere indicar con ello cierta cohesión creadora lírica, la denominación es inexacta".

Ferreres plantea también algunas de las características que podrían definir a quienes participan de la generación; entre otras, su afán de estudiar los clásicos españoles. Indica que, al igual que Diego, Salinas y Guillén, Alonso consigue al fin una cátedra de literatura, debido a su empeño e interés particular. Asimismo, para ejemplificar sus afirmaciones abunda en este sentido: "Dámaso Alonso acepta el encargo de la fatigosa edición de El Enquiridión, de Erasmo, mientras su predilección va hacia Gil Vicente ... hacia el Arcipreste de Hita, que le obsesiona, hacia tantos otros ..." Por último, dado que da a conocer los títulos de los libros iniciales de la generación, menciona Poemas puros y poemillas de la ciudad (Madrid, 1921).

5.6 José María Souvirón, "Con los debidos respetos" (1958)

Crónica. Tono personal, 315-319 pp.

Se trata de una breve nota melancólica, en recuerdo tanto de Aleixandre como de Dámaso, con cierto tono laudatorio: "No puedo veros, a pesar de todos los méritos y de todos los respetos, como dos cuasipatriarcas [se refiere a su 60 cumpleaños] de las letras españolas. ¿No sois, acaso, todavía, "la joven poesía" nacional? ... maestros ... esto sí que lo sois ... desde el mismo primer día”.

Resulta interesante esta especie de crónica en tanto remite a situaciones y espacios en los cuales coincidieron Alonso, Alberti, José María de Cossío, García Lorca y Villalón. También se hace hincapié en el papel de Alonso: “Yo estaba entusiasmado con tu magisterio. Me causabas un respeto imponente ... sin perderlo, te sentí de inmediato como amigo, tan campechano, sabio, afable y diverso como ahora y en los tiempos de en medio ..." 
Poemas (acrósticos). “Vicente”, “Federico" y "Dámaso”, 324-325 pp.

En este apartado, a riesgo de pecar de parcial o de interpretar superficialmente el texto de Cela, vale la pena reproducirlo, teniendo en cuenta su brevedad:

\author{
Día a día \\ A través de los largos silencios, \\ Mientras los viejos arreglan sus confusas cuentas con Dios y las mujeres prepa- \\ ran, con todo mimo, sus atuendos de luto, \\ Arde la llama -Dámaso, la luminaria- \\ Semilla de la que nace, día a día, \\ Otra vez todavía, el misterioso dibujito que todos llevamos, como una resigna- \\ da y alegre enfermedad, en la tierna yema de los dedos.
}

La llama es el modelo a seguir, el maestro que guía con la luz del entendimiento, "Dámaso, la luminaria", pero que se renueva "día a día”. El permanente diálogo con Dios de Alonso, las mujeres que pueblan sus poemas aparecen también como referentes, entre otros posibles.

\title{
5.8 José María Valverde, "Dos visitas" (1958)
}

Crónica/memoria. Dos apartados: “Visita a Vicente" y “Visita a Dámaso", 328$331 \mathrm{pp}$.

Relatando dos visitas (de nuevo a Aleixandre, a Alonso, es decir, a los poetas de la generación que no marcharon al exilio), Valverde relata el aspecto de quienes habitaban la casa de Dámaso, vecino suyo: Petra, la madre, Eulalia, la mujer. Y además, retrata el mundo de Alonso, entre papeles escritos y visitantes. Vale más leer sus impresiones:

\begin{abstract}
... Dámaso que leía versos sacando el labio, con su voz rica de timbres y exacta de fonética; ... las cartas de los poetas lejanos ... los visitantes, mitad entrañables, mitad incongruentes; vates filólogos y entreverados, castizos entre exóticos, alternando los turnos de conversación y aún los idiomas... Dámaso estaba en medio, cansado de trabajar, meticuloso, con una mano para el saber y otra para el imaginar.
\end{abstract}

5.9 José Caballero Bonald, “Hijos de la ira” (1958)

Poema. Versos mayormente heptasílabos, 341-343 pp.

En pretendido homenaje, este autor escribe un poema homónimo al libro de Alonso de 1944. Hay una clara referencia al desamparo, a la lucha interna del hombre que trasciende a su enfrentamiento permanente con el mundo en un sentido metafísico, con directos referentes de la tradición religiosa judeocristiana ("duermo conspirando conmigo, levantando / setenta veces siete / la bandera del sueño, la culpable / rapiña de mi alma"). La interpelación a la madre, por otra parte, lo acerca aún más al poemario de Alonso, y el último verso no deja de confluir en el multi referido diálogo con la divinidad, suerte de reclamo: “Defiéndame Dios de mí". 


\subsection{Leopoldo Panero, "Dámaso Alonso en su montaña" (1958)}

Reflexión/crónica. Sobre el papel de Alonso en la crítica literaria española, 364369 pp.

A partir de una alegoría, relatando un paseo en compañía de Dámaso Alonso, se remite a la enorme cantidad de textos críticos que ha realizado Alonso, y preponderantemente, a su importancia en la crítica española contemporánea: “... sin él ... la crítica española sería todavía menos de lo que es: sería, en cualquier caso, muy otra y distinta. ... Después de Azorín, después de Ortega, sólo Dámaso Alonso ha ejercido y está ejerciendo una influencia tan real y tan honda en nuestras letras"

Y, pretendiendo comprender el enorme y diverso ámbito sobre el que Alonso se detuvo a escribir, señala: “... con esa voz como asombrada de sí misma que Dámaso tiene ... la de su poesía ... la de su andar y desandar la vida, desde el manuscrito medieval a la vespertina mujer de la alcuza, desde el vinillo aloque a la «a» más abierta o cerrada ..."

\subsection{Joan Perucho, "A Dámaso Alonso" (1958)}

Poema. Escrito en catalán, 374 p.

En estrecha relación con el poema siguiente, se pretende establecer un diálogo, yo-tú, con la figura de Alonso-poeta. Sin embargo, a diferencia de los demás poemas, estos versos se formulan a partir del reconocimiento, en principio, de la honda voz de Dámaso; pero también denota la experiencia como viajero perpetuo de Perucho, que lo distancia y, al tiempo, lo acerca aún más al poeta (Alonso): “Lo voy a encontrar primero en sus versos".

\subsection{2 Ángel Crespo, "A Dámaso Alonso" (1958)}

Poema. Endecasílabos, 404-406 pp.

Como parte del conjunto "Poemas de ver un río", este poema se formula como una reflexión, como si el poeta, desdoblado en Dámaso, se detuviera, quisiera dar marcha atrás, volver: “'Acaso no soy otro? ... Si yo-viento me era, ¿puedo acaso / yo-Dámaso, volver al que antes fuera?" Con referencias teológicas y la formulación constante de preguntas en el mismo sentido, el poeta termina diciendo, en directa interpelación a Alonso, en el mismo sentido quizá del diálogo poeta/dios que he referido: “... antes dime, Dámaso, si al viento / puedo llamarle Dios, pues ya se acerca / y creo que esta vez estamos solos."

\subsection{3 "De los siglos oscuros al de Oro" (1958)}

Reseña. Aparece sin firma, por lo que se adjudica a la redacción de PSA, 436-438 pp.

A través del planteamiento de un panorama de siete siglos de literatura española, entre los siglos X y XVI, plasmados en diversos ensayos y artículos, “Dámaso Alonso ha querido aclarar su personal actitud frente a los específicos 
problemas que lleva consigo la labor de cala y fijación de nuestra literatura ..." Por otra parte, y como consecuencia del sentido crítico que permea en todas sus obras, "se sitúa frente a los temas haciendo jugar idéntico papel al análisis y al estudio que a la cultivada adivinación y al súbito entendimiento".

A pesar de las características propias de una reseña, donde se pretende dar a conocer una obra y entusiasmar al público lector con sus cualidades, algunos de los adjetivos utilizados y las hipérboles pueden resultar exageradas a nuestra mirada del siglo XXI, pero no dejan de basarse en una capacidad crítica (la de Dámaso) difícil de refutar.

\subsection{Fernando Huarte, "Bibliografía de Dámaso Alonso" (1958)}

Bibliografía. Se divide en dos apartados, de Dámaso Alonso y sobre él, y éstos a su vez en obra literaria y científica, de modo genérico, 467-518 pp.

En este apartado se reproduce, en principio (ampliada, revisada) la bibliografía compilada por Huarte que apareció publicada en la revista Ínsula, en el número 138-139.

Destaca la ayuda del propio autor en su elaboración, además del hecho, explicitado, de que la mayor parte de las referencias han sido tomadas de los documentos originales.

Ahora bien, el segundo apartado, inédito, “Sobre Dámaso Alonso", a pesar de su "improvisación" no deja de sorprender por su extensión, más de 26 páginas a doble columna, cerca de 600 referencias que comprenden de 1921 a 1958, lo que denota el rigor de su compilador.

\section{Conclusiones}

Tras este peregrinar de páginas y aproximaciones, lo que queda es la antología que Cela pretendió realizar sobre el 27, desde Guillén hasta Altolaguirre, más otros poetas periféricos. El proyecto queda suficientemente esbozado en la correspondencia con Prados, pero no las razones de su fracaso.

Con el afán de plantear una posible respuesta, creo que el hecho de que sólo se editara al cabo el homenaje/antología a tres poetas (dos de ellos viviendo en España, consagrados en vida; Lorca muerto) se debió a la situación política, esto es, al franquismo y su censura.

De todos es sabido que Cela fue capaz, merced a sus contactos, su fama y su extraordinaria inteligencia pública, de capear la censura en muchos momentos, con sus más y sus menos, lo que permitió que PSA se consolidara como una revista, en muchos sentidos, de apertura para quienes, desde el exilio, querían participar de la cultura española de posguerra. Sin embargo, parece claro que sus esfuerzos no siempre rindieron frutos, pues en el caso de la antología del 27, nunca se editó, así como tampoco aparecieron las participaciones de los poetas en PSA que Cela había mencionado.

Otra explicación plausible, complementaria de la anterior, refiere el hecho de que Cela, como ha quedado demostrado por su participación en la guerra del lado falangista, su trabajo como censor (Cela solía restarle importancia a estos sucesos), amén del hecho, incontrovertible, de que permaneciera en España tras la 
derrota de la segunda república en 1939 y pudiera vivir, como muy pocos, de la escritura, Cela, entonces, teniendo una posición más cercana a la derecha (lo que no resta valor a sus intentos de relación e invitación a los españoles exiliados, dada su inteligencia para apreciar la capacidad intelectual viniera de donde viniese), a pesar de sus aproximaciones (correspondencia, colaboraciones en su revista, ediciones memorables como la de Signos del ser, de Emilio Prados cuyo colofón, fechado el 24 de abril de 1962, coincide con la muerte del poeta en México) se mantiene hasta cierto punto al margen, esto es, no consolida estos lazos ni tampoco, como puede apreciarse en los índices generales de la revista, publica en demasía a quienes viven exiliados fuera de España (y me refiero a quienes, en muchos sentidos, resultaban más incómodos, es decir, eran más perseguidos por la censura).

A pesar de todo, el homenaje a Aleixandre, Alonso y Lorca, a fin de cuentas, resulta un ejemplar extraordinario: por su amplitud, por quienes colaboran en él (de diversos signos, de procedencias y edades distintas), por la coincidencia en relación a la importancia de estos tres poetas para la poesía española de mediados del siglo XX.

En cuanto a la presencia de Dámaso Alonso en el volumen, sólo habría que lamentar una falta de rigor en las aproximaciones, la mayor parte de las cuales no ahondan en el análisis de su obra o figura, sirviendo (eso sí) de testimonio de su quehacer, esencialmente docente, en la influencia directa en unos y otros a partir de su trato (o lectura), y más allá, reconociendo, como lo evidencian los variados poemas dedicados a él, la influencia que de alguna manera ejercía en los poetas de la época.

Como señala Pedro Salinas ${ }^{13}$, en referencia a la Poesía española (Alonso, 1950) que edita Dámaso Alonso, "magnífico... ha trabajado como un león y con fruto espléndido. Este libro que acaba de salir es muy bueno... Me da la impresión de estar en el momento más pleno y feliz de su producción de crítico. El crítico mejor que ha tenido la poesía española desde... ¿cuándo? Por supuesto que en este siglo no hay quien le llegue". (Soria Olmedo, 1991:12).

De este modo, crítico y poeta, destacando esto último por el anhelo del propio Dámaso Alonso, pero la crítica avasallando en términos cuantitativos, quedan esbozados y definidos, en muchos sentidos, en esta antología, merecida por supuesto, y referencia obligada para el estudio de su obra.

\section{BIBLIOGRAFÍA}

Alonso, Dámaso (1956): Antología: crítica, Madrid, Escelicer.

Alonso, Dámaso (1990): Dámaso Alonso, introducción, selección y bio-bibliografía de Dámaso Santos, Málaga, Centro Cultural de la generación del 27.

Alonso, Dámaso (1991): Oscura noticia. Hombre y Dios, Madrid, Espasa Calpe, edición de Antonio Chicharro.

Alonso, Dámaso (1950): Poesía española, Madrid, Gredos.

Alonso, Dámaso (1958): "Poesías ocasionales", en Papeles de Son Armadans, año III, tomo XI, núm. XXXII-XXXIII, Palma de Mallorca, PSA, pp. 126-150.

\footnotetext{
${ }^{13}$ Quien por cierto no aparece referido, ni colaboró nunca en PSA.
} 
Alonso, Dámaso (1965): “Una generación poética”, en Poetas españoles contemporáneos, Madrid, Gredos, pp. 166-169 [primera edición, 1952; el artículo se publicó por primera vez en 1948].

Caballero Bonald, José (1958): "Hijos de la ira" en Papeles de Son Armadans, año III, tomo XI, núm. XXXII-XXXIII, Palma de Mallorca, PSA, pp. 341-343.

Cano, José Luis (1970): La poesía de la Generación del 27, Madrid, Guadarrama.

Cano, José Luis (1980): "Prólogo", en Antología poética, Barcelona, Plaza y Janés.

Carreira, Antonio (1996): "Presentación de un epistolario de amistad", en El Extramundi y los Papeles de Iria Flavia, año II, núm. V, primavera Iria Flavia, Fundación Camilo José Cela, pp. 11-40.

Cela, Camilo José (1958a): “Acrósticos para tocar campanas en un triple homenaje”, en Papeles de Son Armadans, año III, tomo XI, núm. XXXII-XXXIII, Palma de Mallorca, PSA, pp. 324-325.

Cela, Camilo José (1996): “Cartas entre Emilio Prados y Camilo José Cela”, en El Extramundi y los Papeles de Iria Flavia, año II, núm. V, primavera, Iria Flavia, Fundación Camilo José Cela, pp. 41-166.

Cela, Camilo José (1958b): "Loa de los jóvenes sesentones y llanto por el poeta muerto en flor", en Papeles de Son Armadans, año III, tomo XI, núm. XXXII-XXXIII, Palma de Mallorca, PSA, pp. 115-118.

Cernuda, Luis (1981): Epistolario inédito, Sevilla, Compás, edición de Fernando Ortiz.

Chicharro Chamorro, Antonio (2002): "Humanísima letra (Algunas claves de la poesía social", en Aviso para navegantes (crítica literaria y cultural), Granada, Alhulia, pp. 73-80.

Chicharro Chamorro, Antonio (1991): "Introducción", Oscura noticia. Hombre y Dios, Madrid, Espasa Calpe, pp. 11-42.

Crespo, Ángel (1958): "Poemas para ver un río", en Papeles de Son Armadans, año III, tomo XI, núm. XXXII-XXXIII, Palma de Mallorca, PSA, pp. 404-409.

Diego, Gerardo (1932): Poesía española: Antología 1915-1931, Madrid, Signo.

Diego, Gerardo (1934): Poesía española: Antología (Contemporáneos), Madrid, Signo [edición ampliada].

Diego, Gerardo (1959): Poesía española contemporánea 1901-1934, Madrid, Taurus [reedición de la anterior].

"Los dos últimos libros de Vicente Aleixandre y Dámaso Alonso" (1958): en Papeles de Son Armadans, año III, tomo XI, núm. XXXII-XXXIII, Palma de Mallorca, PSA, pp. 433-438.

Ferreres, Rafael (1958): "Sobre la generación poética de 1927", en Papeles de Son Armadans, año III, tomo XI, núm. XXXII-XXXIII, Palma de Mallorca, PSA, pp. 301-314.

García García, Miguel Ángel (2001): El Veintisiete en vanguardia: hacia una lectura histórica de las poéticas moderna y contemporánea, Valencia, Pre-textos.

García Lorca, Federico (1958): "Postal", en Papeles de Son Armadans, año III, tomo XI, núm. XXXII-XXXIII, Palma de Mallorca, PSA, pp. 119.

Guillén, Jorge (1958): "Algunos poetas amigos", en Papeles de Son Armadans, año III, tomo XI, núm. XXXII-XXXIII, Palma de Mallorca, PSA, pp. 151-165.

Huarte, Fernando (1958): "Bibliografía de Dámaso Alonso", en Papeles de Son Armadans, año III, tomo XI, núm. XXXII-XXXIII, Palma de Mallorca, PSA, pp. 463-518.

León Felipe (1958): “Cuatro poemas, con epígrafe y colofón”, en Papeles de Son Armadans, año III, tomo XI, núm. XXXII-XXXIII, Palma de Mallorca, PSA, pp. 189-194.

Marías, Julián (1975): "Generaciones: los cambios del mundo", en Literatura y generaciones, Madrid, Espasa-Calpe, pp. 173-178.

Panero, Leopoldo (1958): “Dámaso Alonso en su montaña”, en Papeles de Son Armadans, año III, tomo XI, núm. XXXII-XXXIII, Palma de Mallorca, PSA, pp. 364-369. 
Perucho, Joan (1958): “Dos homenaiges" en Papeles de Son Armadans, año III, tomo XI, núm. XXXII-XXXIII, Palma de Mallorca, PSA, pp. 372-374.

Prados, Emilio (1996): “Cartas entre Emilio Prados y Camilo José Cela", en El Extramundi y los Papeles de Iria Flavia, año II, núm. V, primavera Iria Flavia, Fundación Camilo José Cela, pp. 41-166.

Rodríguez, Juan Carlos (2001): “El mito de la poesía de vanguardia: el 27. Poesía de la miseria/miseria de la poesía", en La norma literaria, Madrid, Diputación Provincial de Granada, pp. 259-300.

Soria Olmedo, Andrés (1991): “Dámaso Alonso en el epistolario Salinas-Guillén", en Ínsula, núm. 530, febrero, pp. 11-12.

Souvirón, José María (1958): “Con los debidos respetos”, en Papeles de Son Armadans, año III, tomo XI, núm. XXXII-XXXIII, Palma de Mallorca, PSA, pp. 315-319.

Valverde, José María (1958): "Dos visitas", en Papeles de Son Armadans, año III, tomo XI, núm. XXXII-XXXIII, Palma de Mallorca, PSA, pp. 329-331. 